\title{
Assaying Rho GTPase-dependent processes in Dictyostelium discoideum
}

Maja Marinović1, Huajiang Xiong ${ }^{2}$, Francisco Rivero ${ }^{3}$ and Igor Weber $^{1}$

1. Division of Molecular Biology, Ruđer Bošković Institute, Zagreb

Croatia.

2. Department of Biochemistry, University of Oxford, Oxford, United Kingdom

3. Centre for Atherothrombosis and Metabolic Disease, Hull York Medical School, Faculty of Health Sciences, University of Hull, Hull, United Kingdom

\section{Corresponding authors Igor Weber}

Division of Molecular Biology, Ruđer Bošković Institute

Bijenička cesta 54, 10000 Zagreb, Croatia

Tel: ++385-1-4571219

Mobile: ++385-98-437148

Email: iweber@irb.hr

\section{Francisco Rivero}

Centre for Atherothrombosis and Metabolic Disease

The Hull York Medical School, Faculty of Health Sciences, University of Hull Cottinghm Road, HU6 7RX Hull, United Kingdom

Tel: +44 1482466433

Email: Francisco.rivero@hyms.ac.uk

Running title: Rho-dependent processes in $D$. discoideum

\section{Summary}

The model organism $D$. discoideum is well-suited to investigate basic questions of molecular and cell biology, particularly those related to the structure, regulation and dynamics of the cytoskeleton, signal transduction, cell-cell adhesion and development. $D$. discoideum cells make use of Rho-regulated signaling pathways to reorganize the actin cytoskeleton during chemotaxis, endocytosis and cytokinesis. In this organism the Rho family encompasses 20 members, several belonging to the Rac subfamily, but there are no representatives of the Cdc42 and Rho subfamilies. Here we present protocols suitable for monitoring the actin polymerization response and the activation of Rac upon stimulation of aggregation competent cells with the chemoattractant cAMP, and for monitoring the localization and dynamics of Rac activity in live cells. 
This is a post-peer-review, pre-copyedit version of an article published in Methods in molecular biology, 1821, pp.371-392. The final authenticated version is available online at: https://doi.org/10.1007/978-1-4939-8612-5_25

Keywords: Actin polymerization, cAMP, chemotaxis, Dictyostelium, fluorescent probes, FRET, GTPase-binding domain, pull-down assay, Rac 


\section{Introduction}

\subsection{Dictyostelium discoideum as a model organism}

Dictyostelium discoideum is a simple eukaryotic microorganism whose natural habitat is the deciduous forest soil where free-living amoebas feed on bacteria and multiply by equal mitotic division. Exhaustion of the food source triggers a developmental program in which more than 100,000 cells aggregate by chemotaxis toward cAMP to form a multicellular structure. Differentiation and morphogenesis result in the formation of a fruiting body composed of a mass of spores supported by a stalk made of vacuolized dead cells. Numerous advantages make $D$. discoideum a widely accepted and well-suited model organism to investigate basic questions of molecular and cell biology, particularly those related to the structure, regulation and dynamics of the cytoskeleton, signal transduction, cell-cell adhesion and development (1). More recently $D$. discoideum is being employed as a model to study the mechanisms of infection by pathogenic bacteria and the molecular causes of human diseases (2). $D$. discoideum has a short life cycle, is easy to cultivate, grows in inexpensive media, can be harvested in large amounts and is amenable to a variety of biochemical and molecular and cell biological techniques $(3,4)$. Its genome, completely sequenced and largely annotated, can be easily manipulated by means of a growing list of molecular genetics techniques that have allowed considerable advances in the study of biological processes.

\subsection{Rho GTPases in D. discoideum}

Like other eukaryotic cells $D$. discoideum makes use of Rho-regulated signal transduction pathways to reorganize its cytoskeleton during chemotaxis and other processes such as endocytosis and cytokinesis. In $D$. discoideum the Rho family encompasses 20 members. Rho signaling is complemented in this organism with more than 100 regulators (exchange factors, GTPase activating proteins and guanine nucleotide dissociating inhibitors) and about 80 effectors or components of effector complexes (Scar, WASP, formins, PAK kinases, IQGAP-related proteins, etc). Based on phylogenetic analyses, several Rho GTPases can be grouped in the Rac 
subfamily: Rac1a, Rac1b, Rac1c, RacF1, RacF2, and more loosely RacB and the GTPase domain of RacA (the D. discoideum RhoBTB ortholog). All other $D$. discoideum Rho GTPases were named Rac for historical reasons but they do not have a clear affiliation, although some are closer to Rac than to members of other subfamilies. There are no representatives of the Cdc42, Rho or other subfamilies in D. discoideum (5).

Like in other organisms, knockout, overexpression and gain-of-function mutants have been used to investigate the physiological roles of $D$. discoideum Rho GTPases. However, the presence of multiple Rac proteins, some of them as very closely related isoforms, has presented a challenge for the elucidation of their function, because of potential functional redundancy. Nevertheless, the evidence accumulated so far implicates Rho GTPases in the regulation of chemotaxis and cell motility, endocytosis and vesicle trafficking, cytokinesis and development in D. discoideum. The reader is referred to a recent comprehensive review on Rho signalling in $D$. discoideum for further details (6).

\subsection{Assaying Rac-dependent processes in D. discoideum}

Because it would be impossible to provide detailed methods to investigate all relevant processes in which Rho GTPases have been implicated in D. discoideum, here we will restrict ourselves to protocols for monitoring the actin polymerization response, the activation of Rac upon cAMP stimulation of aggregation competent cells, and the localization and dynamics of Rac activity in live cells. For more detailed investigation of actin localization, chemotaxis, endocytosis and other processes the reader is referred to other sources $(3,4)$.

\subsubsection{Filamentous actin content}

The filamentous (F-)actin content is quantitated by fluorescently labeled phalloidin staining of formaldehyde-fixed pelleted material, an adaptation to $D$. discoideum cells (7) of the method originally devised for neutrophils (8). The method has been applied extensively to monitoring the actin polymerization response induced by CAMP in aggregation competent cells in a variety of circumstances. F-actin exhibits a 
characteristic biphasic curve upon agonist stimulation. During the first peak, at $5 \mathrm{sec}$, the amount of F-actin approximately doubles. This peak is very short and correlates with the cringe reaction in which the cells round up and produce a uniform cortical accumulation of F-actin. The second peak is significantly broader and lower, shows a maximum at 30-60 sec and corresponds to the emergence of pseudopods and cell movement. The actin polymerization response parallels in time and magnitude that of Rac activation, on which it depends (9-11) and therefore constitutes an excellent tool to monitor alterations in Rac-dependent signaling pathways (Fig. 1A).

\subsubsection{Rac activation assay}

The Rac activation (or pull-down) assay is an adaptation for $D$. discoideum of the method described by Benard et al. (12) for the determination of Rac and Cdc42 activation in chemoattractant-stimulated human neutrophils. The method makes use of a fusion protein of glutathione-S-transferase (GST) and the Rho GTPase binding domain of an effector molecule to capture active Rac in cell lysate. In D. discoideum this method has been applied to the determination of activated Rac1, RacB and RacC $(9-11,13)$. In principle the method could be adapted to determine the activity of any other Rac, provided a GST fusion with a specific GTPase-binding domain (GBD) and a specific antibody to detect the Rac by Western blot are available. However, Rho GTPase-binding domains of potential use have been identified for a very limited number of $D$. discoideum Racs (Rac1a/1b/1c, RacA, RacB, RacC and RacF1/2) only, and they include WASP and related proteins, PAK kinases and IQGAPs (Table 1 and ref. 14). We have tested the GTPase binding domains of $D$. discoideum WASP and PAKb as well as human PAK1 for the pull-down assay of activated Rac1 and have obtained better results with WASP $(11,13)$. WASP has also been used by Han et al. for the determination of RacC (10). Park et al. have used PAKa to pull-down active $\operatorname{RacB}(9)$.

Another limitation is posed by the unavailability of good antibodies against $D$. discoideum Racs. At present only endogenous Rac1 can be detected in Western blots after a pull-down assay $(11,13,15)$. Two approaches have been taken to overcome this problem. Han et al. have resorted to the use of a strain that expresses 
a fluorescent protein fusion of RacC and detected the activated protein with an antigreen fluorescent protein (GFP) antibody (10). Park et al. replaced endogenous RacB with a gene encoding a myc-tagged RacB under the control of the endogenous promoter (9), an approach that will be very useful if applied in future to the other members of the Rac family.

\subsubsection{Monitoring Rac activity in live cells}

A limitation of the pull-down assay is that it provides a measurement of the total activity of a given Rac in a population of cells and therefore does not permit the spatial and temporal monitoring of Rac activation within individual living cells. Probes based on fluorescence resonance energy transfer (FRET) have been developed and applied to $D$. discoideum (10, 16-19). The first FRET probe for monitoring of RacC activity in vivo consisted of cyan fluorescent protein (CFP)-RacC and yellow fluorescent protein (YFP)-B-GBD (the GBD of WASP) (10). The main obstacle encountered when attempting to image FRET probes in live cells is a prohibitively long integration time needed to obtain an acceptable signal-to-noise ratio (19). In order to be able to follow the Rac dynamics during fast intracellular processes, investigators resorted to the use of simpler probes based on fluorescently labeled Rac-binding domains (Table 1). These probes were mostly used to monitor the activity of Rac1 and RacC, but appear to have different degrees of specificity. Interestingly, the fluorescently labeled Rac1 effector DGAP1 displayed an opposite localization to PAK-GBD-based probes, suggesting that the entire population of active Rac is not detected by the use of standard probes (14).

\section{Materials}

All media and buffers are prepared using deionized water $\left(\mathrm{dH}_{2} \mathrm{O}\right)$, filtered through an ion-exchange unit.

\subsection{Culture and selection of $D$. discoideum cells}

D. discoideum cells are cultured in nutrient medium in suspension on a rotary shaker (160 rpm) at $21^{\circ} \mathrm{C}$. Cells are harvested and washed at room temperature by 
centrifugation at $500 \times g$ for 3 min. When analyzing different strains, it is recommended that cells be cultivated under the same conditions for some days preceding the assays. For the assays described here cells should be taken from axenically growing or "log phase" cultures (up to $2 \times 10^{6}$ cells $/ \mathrm{mL}$ ). Dilute cultures the day before in order to have the necessary number of log phase cells.

1. AX Medium is available from Formedium ${ }^{\mathrm{TM}}$ in powder form. Suspend $40.4 \mathrm{~g}$ in 1 $\mathrm{L}$ of $\mathrm{dH}_{2} \mathrm{O}$ and autoclave.

2. HL5 Medium without glucose supplemented with vitamins and microelements is available from Formedium ${ }^{\mathrm{TM}}$ in powder form. Suspend $22 \mathrm{~g}$ of HL5 medium and $18 \mathrm{~g}$ of maltose in $1 \mathrm{~L}$ of $\mathrm{dH}_{2} \mathrm{O}$ and autoclave. AX and HL5 media can be used indistinguishably.

3. $100 \times$ ampicillin/streptomycin stock solution: $5 \mathrm{mg} / \mathrm{mL}$ ampicillin, $4 \mathrm{mg} / \mathrm{mL}$ streptomycin sulfate in sterile $\mathrm{dH}_{2} \mathrm{O}$, filter sterilize $(0.2 \mu \mathrm{m}$ pore diameter), store at $4^{\circ} \mathrm{C}$.

4. $10 \mathrm{mg} / \mathrm{mL}$ G418 stock solution in sterile $\mathrm{dH}_{2} \mathrm{O}$, filter sterilize $(0.2 \mu \mathrm{m}$ pore diameter), store at $4^{\circ} \mathrm{C}$.

5. Soerensen phosphate buffer: $2 \mathrm{mM} \mathrm{Na}_{2} \mathrm{HPO}_{4}, 14.6 \mathrm{mM} \mathrm{KH}_{2} \mathrm{PO}_{4}, \mathrm{pH}$ 6.0. Autoclave.

\subsection{Determination of F-actin}

1. Tetramethylrhodamine isothiocyanate (TRITC)-labeled phalloidin (Sigma P1951). Dissolve to $0.1 \mathrm{mg} / \mathrm{mL}$ in methanol to obtain a $76.6 \mu \mathrm{M}$ stock solution. Store at $-20^{\circ} \mathrm{C}$ (see Note 1 ).

2. Actin polymerization stop solution: $3.7 \%$ formaldehyde, $0.1 \%(v / v)$ Triton $X-100$, $20 \mathrm{mM}$ potassium phosphate, $10 \mathrm{mM}$ PIPES, $5 \mathrm{mM}$ ethylene glycol-bis( $\beta$ aminoethyl ether)-N,N,N',N'-tetraacetic acid (EGTA), $2 \mathrm{mM} \mathrm{MgCl}_{2}$. Adjust pH to 6.8 with $1 \mathrm{~N} \mathrm{KOH}$. Store aliquots at $-20^{\circ} \mathrm{C}$. TRITC-phalloidin is added to $0.25 \mu \mathrm{M}$ final concentration fresh before starting the experiment (see Note 2).

3. $0.1 \mathrm{mM}$ cAMP stock solution. Dissolve cAMP in Soerensen buffer. Store aliquots at $-20^{\circ} \mathrm{C}$.

4. Methanol (see Note 1).

5. Fluorimeter (PTI or equivalent). 


\subsection{Rac activity assay}

1. E. coli strain (e.g. XL-1 blue or BL21) carrying a pGEX series vector (GE Healthcare) with the GBD domain of $D$. discoideum WASP cloned in frame to GST. The plasmid is available from the authors or can be easily constructed using standard molecular biology procedures. A cDNA encoding WASP is available from the Dicty Stock Centre (http://dictybase.org/StockCenter/StockCenter.html).

2. Luria broth (LB): dissolve $10 \mathrm{~g}$ of Bacto-tryptone, $5 \mathrm{~g}$ of yeast extract and $10 \mathrm{~g}$ of $\mathrm{NaCl}$ in $600 \mathrm{~mL}$ of $\mathrm{dH}_{2} \mathrm{O}$, adjust $\mathrm{pH}$ to 7.5 with $1 \mathrm{~N} \mathrm{NaOH}$, complete to $1 \mathrm{~L}$ with $\mathrm{dH}_{2} \mathrm{O}$, autoclave.

3. $100 \mathrm{mg} / \mathrm{mL}$ ampicillin in sterile $\mathrm{dH}_{2} \mathrm{O}$, filter sterilize $(0.2 \mu \mathrm{m}$ pore diameter $)$, store aliquots at $-20^{\circ} \mathrm{C}$.

4. $1 \mathrm{M}$ isopropyl- $\beta$-D-thiogalactopyranoside (IPTG) in sterile $\mathrm{dH}_{2} \mathrm{O}$, filter sterilize $\left(0.2 \mu \mathrm{m}\right.$ pore diameter), store aliquots at $-20^{\circ} \mathrm{C}$.

5. Glutathione Sepharose 4B beads (GE Healthcare).

6. Bacterial lysis buffer: $50 \mathrm{mM}$ Tris- $\mathrm{HCl}$ pH 8.0, $300 \mathrm{mM} \mathrm{NaCl}, 10 \mathrm{mM} \mathrm{MgCl}$. Add fresh, prior to use, $4 \mathrm{mM}$ dithiotreitol (DTT), protease inhibitor cocktail (Roche), $5 \mathrm{mg} / \mathrm{mL}$ lysozyme.

7. Washing buffer: $50 \mathrm{mM}$ Tris- $\mathrm{HCl}, \mathrm{pH} 8.0,1 \mathrm{M} \mathrm{NaCl}, 10 \mathrm{mM} \mathrm{MgCl}$. Add fresh, prior to use, $4 \mathrm{mM}$ DTT.

8. $2 \times$ SDS sample buffer: $0.125 \mathrm{M}$ Tris $-\mathrm{HCl}$ pH $6.8,4 \%(\mathrm{w} / \mathrm{v})$ sodium dodecylsulfate (SDS), 20\% (v/v) glycerol, 10\% (v/v) 2-mercaptoethanol, $0.004 \%$ (w/v) bromophenol blue.

9. $5 \times$ Reaction buffer: 50 mM HEPES pH 7.5, $500 \mathrm{mM} \mathrm{NaCl}, 100 \mathrm{mM} \mathrm{MgCl}$, 2.5\% (v/v) Triton X-100. Add fresh, prior to use: 1 mM DTT, protease inhibitor cocktail (Roche).

10. $1 \times$ Reaction buffer: prepare from $5 \times$ reaction buffer by dilution with sterile $\mathrm{dH}_{2} \mathrm{O}$.

11. Spin columns, $0.9 \mathrm{~mL}$ capacity with screw caps and press-on bottom plugs (Thermo Scientific Pierce).

12. D. discoideum Rac1 specific antibody 273-461-3 (15) and horse radish peroxidase-coupled anti-mouse secondary antibody. 
13. Spectrophotometer.

14. Sonicator: UP200S (Hielscher Ultrasonics $\mathrm{GmbH}$ ) or equivalent.

15. Tube rotator.

16. Standard equipment, reagents and buffers for SDS-polyacrylamide gel electrophoresis (PAGE), Coomassie staining and Western blot.

\subsection{Monitoring Rac activity in live cells}

1. CDNA template for DYFP is available from the authors.

2. cDNA template for D. discoideum PAKa GBD is available from the authors.

3. Custom-made PCR primers.

4. Cloning vector pDM304, available from the Dicty Stock Center (http://dictybase.org/StockCenter/StockCenter.html).

5. Standard equipment, reagents and enzymes for PCR.

6. Standard equipment, reagents and buffers for agarose gel electrophoresis and ethidium bromide staining.

7. UV transilluminator (Syngene or equivalent).

8. Gel extraction kit (Qiagen or equivalent).

9. Spel, Bglll and Xbal restriction endonucleases.

10. PCR purification kit (Qiagen or equivalent).

11. Calf intestinal alkaline phosphatase $(1 \mathrm{U} / \mu \mathrm{L})$ supplied with $10 \times$ dephosphorylation buffer (Invitrogen or equivalent).

12. T4 DNA ligase (5 Weiss $U / \mu \mathrm{L}$ ) supplied with $10 \times \mathrm{T} 4$ ligase buffer and $50 \%$ polyethylene glycol (PEG) solution (Thermo Scientific or equivalent).

13. Electrocompetent E.coli strain (e.g. homemade DH5a or other suitable).

14. Electroporation cuvettes, 2-mm gap.

15. Electroporator: Gene Pulser Xcell ${ }^{\mathrm{TM}}$ (Biorad) or equivalent.

16. SOC medium: $0.5 \%(\mathrm{w} / \mathrm{v})$ yeast extract, $2 \%(\mathrm{w} / \mathrm{v})$ tryptone, $10 \mathrm{mM} \mathrm{NaCl}, 10$ $\mathrm{mM} \mathrm{MgCl}_{2}, 2.5 \mathrm{mM} \mathrm{KCl} 20 \mathrm{mM} \mathrm{MgSO}_{4}, 20 \mathrm{mM}$ glucose in $\mathrm{dH}_{2} \mathrm{O}$, autoclave.

17. Luria broth (LB) (see Subheading 2.3 item 2).

18. $100 \mathrm{mg} / \mathrm{mL}$ ampicillin stock solution (see Subheading 2.3 item 3). 
19. LB agar plates supplemented with ampicillin: add $15 \mathrm{~g}$ of agar in $1 \mathrm{~L}$ of LB medium, autoclave, cool down to $50^{\circ} \mathrm{C}$, add $1 \mathrm{~mL}$ of ampicillin stock solution. Pour into $10-\mathrm{cm}$ plates, let cool down and store plates at $4^{\circ} \mathrm{C}$.

20. Plasmid miniprep kit (Qiagen or equivalent).

21. Glass bottom culture dishes 35-mm, \#1.5 (MatTek or equivalent). Selfmade open chambers can also be used (see Note 3).

22. $0.15 \mathrm{mM}$ cAMP stock solution. Dissolve cAMP in Soerensen buffer. Store aliquots at $-20^{\circ} \mathrm{C}$.

23. $50 \mathrm{mM}$ folic acid stock solution in $0.1 \mathrm{~N} \mathrm{NaOH}$. Store in the dark at $4^{\circ} \mathrm{C}$. $\mathrm{A}$ $250 \mu \mathrm{M}$ working solution is freshly made by diluting the stock solution in Soerensen buffer.

24. Confocal laser scanning microscope (Leica TCS SP8 X or other suitable).

25. ImageJ with integrated QuimP (Quantitative image analysis of membrane associated Proteins) plugin (https://imagej.nih.gov/ij/).

\section{Methods}

\subsection{Determination of the relative F-actin content}

Using this method cells are permeabilized immediately by Triton X-100, allowing very rapid fixation (within $1 \mathrm{sec}$ ) by formaldehyde. TRITC-phalloidin binds specifically to Factin. TRITC-phalloidin is methanol-extracted from the Triton insoluble pellet and quantitated fluorimetrically, providing a measurement of the amount of F-actin present in the cell sample. Here we describe the determination of the basal F-actin content of a cell strain relative to a control strain.

1. Harvest and resuspend cells at $2 \times 10^{7}$ cells $/ \mathrm{mL}$ in fresh nutrient medium. Allow cells to recuperate for $30 \mathrm{~min}$.

2. Thaw actin polymerization stop solution and transfer the amount needed into a conical tube. Add TRITC-phalloidin to $0.25 \mu \mathrm{M}$ final concentration (32.6 $\mu \mathrm{L}$ of the $0.1 \mathrm{mg} / \mathrm{mL}$ stock for $10 \mathrm{~mL}$ of stop solution). Dispense $450 \mu \mathrm{L}$ into labeled microcentrifuge tubes (3 replicates for each strain) (see Note 4). 
3. Withdraw three $50-\mu \mathrm{L}$ samples of cell suspension and transfer into tubes containing $450 \mu \mathrm{L}$ of stop solution.

4. Incubate samples with for $1 \mathrm{~h}$ at room temperature in the dark.

5. Spin samples for 5 min at $15,000 \times g$.

6. Carefully remove supernatant without disturbing the pellet. Pellets have a pale pink color.

7. Extract each pellet with $1 \mathrm{~mL}$ of methanol for $1 \mathrm{~h}$ in the dark prior to fluorimetric measurement (excitation $540 \mathrm{~nm}$, emission $565 \mathrm{~nm}$ ). Alternatively allow the extraction to proceed overnight at $-20^{\circ} \mathrm{C}$ in the dark.

8. Determination of total protein content. Withdraw $50-\mu \mathrm{L}$ samples of the cell suspension. Pellet cells for $10 \mathrm{sec}$ at maximum speed in a tabletop centrifuge and remove supernatant. The pellets can be frozen or can be processed immediately for the determination of protein content using a standard method.

9. Normalize the fluorescence values to the protein content of the sample and calculate the F-actin content relative to the control strain.

\subsection{Actin polymerization response upon cAMP stimulation}

The same principle as in Subheading 3.1 is applied to the determination of the time course of F-actin formation upon agonist stimulation.

1. Harvest cells and wash twice with Soerensen buffer.

2. Resuspend cells at $2 \times 10^{7}$ cells $/ \mathrm{mL}$ in Soerensen buffer.

3. Starve cells for 6 to $8 \mathrm{~h}$ at $21^{\circ} \mathrm{C}$ in an Erlenmeyer flask on a rotary shaker (160 rpm).

4. Shortly before starting the experiment thaw actin polymerization stop solution and transfer the amount needed into a conical tube. Add TRITC-phalloidin to $0.25 \mu \mathrm{M}$ final concentration $(32.6 \mu \mathrm{L}$ of the $0.1 \mathrm{mg} / \mathrm{mL}$ stock for $10 \mathrm{~mL}$ of stop solution). Dispense $450 \mu \mathrm{L}$ into labeled microcentrifuge tubes (see Note 4).

5. Transfer $1 \mathrm{~mL}$ of cell suspension into a well of a 24-well plate.

6. Place the 24-well plate on a mini shaker (see Note 5).

7. Collect four $50-\mu \mathrm{L}$ samples and transfer to tubes containing actin polymerization stop solution (see Note 6). These will be the time point 0 measurements. 
8. Stimulate actin polymerization in the remaining $800 \mu \mathrm{L}$ of cell suspension with 8 $\mu \mathrm{L}$ of $0.1 \mathrm{mM}$ cAMP (1 $\mu \mathrm{M}$ final concentration).

9. Immediately collect $50-\mu \mathrm{L}$ samples at following time points: $5,10,15,20,25,30$, 40, 50, 60, 70, 80, 90, 100 and $120 \mathrm{sec}$ after cAMP stimulation (see Note 7). Each sample is dispensed in its corresponding tube containing stop solution.

10. Proceed as in Subheading 3.1, steps 4-7.

11. For the calculations refer the fluorescence values to the value of the 0 time point. Wild type cells usually have a peak of F-actin 1.6-2 times the 0 time point value 5 sec after cAMP stimulation (see Fig. 1A). Alternatively the amount of fluorescence can be normalized to the protein content of the cell suspension. In this case withdraw one sample for protein determination as indicated in Subheading 3.1, step 8.

\subsection{Pull-down assay for activated Rac}

The method makes use of a fusion protein of GST and the Rho GTPase binding domain of an effector molecule. The fusion protein is expressed recombinantly in $E$. coli and is purified by attachment to glutathione agarose. The glutathione Sepharose beads carrying the fusion protein are applied to a cell lysate. The beads are then separated from the lysate followed by washing and elution of the captured active Rac in sample loading buffer. The active Rac is detected by Western blot. The protocol given below is designed for the determination of activated Rac1 using the CRIB (Cdc42 and Rac interactive binding) domain of WASP (11), but can in principle be adapted for the detection of any activated Rho GTPase provided a specific effector is available and the GTPase can be identified on a Western blot.

\subsubsection{Production of GST-WASPCRIB}

1. Innoculate $50 \mathrm{~mL}$ of LB/ampicillin $(50 \mu \mathrm{g} / \mathrm{mL})$ with a single colony of $E$. coli transformed with the pGEX-WASP ${ }^{\mathrm{CRIB}}$ plasmid. Grow overnight at $37^{\circ} \mathrm{C}$.

2. Innoculate $1 \mathrm{~L}$ of $\mathrm{LB} / \mathrm{ampicillin}(50 \mu \mathrm{g} / \mathrm{mL})$ with the overnight culture, determine the optical density of the culture at $600 \mathrm{~nm}\left(\mathrm{OD}_{600}\right)$ and grow at $37^{\circ} \mathrm{C}$.

3. Induce expression with 0.2 mM IPTG when the culture has reached an OD600 around 0.7 . Continue growth at $37^{\circ} \mathrm{C}$ for $2-3 \mathrm{~h}$. 
4. Collect bacteria by centrifugation at $2000 \times \mathrm{g}$ for $10 \mathrm{~min}$ (see Note 8 ). Resuspend bacterial pellet in $10 \mathrm{~mL}$ of pre-chilled lysis buffer supplemented with protease inhibitor cocktail and lysozyme.

5. Sonicate the bacterial suspension 6-10 times for $30 \mathrm{sec}$ at $50-70 \%$ duty cycle on ice (see Note 9).

6. Remove cell debris by spinning at $21,000 \times \mathrm{g}$ for $10-20$ min at $4^{\circ} \mathrm{C}$. Collect supernatant and store aliquots at $-80^{\circ} \mathrm{C}$ (see Note 10$)$.

7. Monitor the efficiency of fusion protein expression and purification by SDSPAGE. Proceed as in steps 4-7 of Subheading 3.3.2 using one spin column and $50 \mu \mathrm{L}$ of glutathione Sepharose slurry. After the last washing step place the spin column in an open microcentrifuge cup and remove residual wash buffer by spinning at $10,000 \times \mathrm{g}$ for $1 \mathrm{~min}$. Place the spin column into a clean microcentrifuge cup, apply $50 \mu \mathrm{L}$ of $2 \times$ SDS sample buffer and spin at 10,000×g for $1 \mathrm{~min}$ to collect the affinity purified GST- WASPCRIB. Denature samples for 5 $\min$ at $95^{\circ} \mathrm{C}$. Examine $15 \mu \mathrm{L}$ of the eluate by SDS-PAGE and Coomassie staining (see Note 11).

\subsubsection{Pull-down of activated Rac upon cAMP stimulation}

Following protocol is devised for the determination of activated Rac1 in one D. discoideum strain during the first $20 \mathrm{sec}$ upon agonist stimulation (see Fig. 1B). If a longer time course is required, increase the amount of cell suspension and Sepharose beads and the number of spin columns accordingly. Start with the preparation of the Sepharose beads loaded with GST-WASPCRIB approximately $2 \mathrm{~h}$ before the end of the starvation period (see Note 10). Except for the Soerensen buffer and the $2 \times$ SDS sample buffer, all other buffers should be chilled.

1. Harvest $D$. discoideum cells and wash twice with Soerensen buffer.

2. Resuspend cells at $2 \times 10^{7}$ cells $/ \mathrm{mL}$ in Soerensen buffer. $6 \mathrm{~mL}$ of cell suspension are required.

3. Starve cells for 6 to $8 \mathrm{~h}$ at $21^{\circ} \mathrm{C}$ in an Erlenmeyer flask on a rotary shaker (160 rpm). 
4. Prepare 5 spin columns, labeled 0,5, 10, 15 and 20. Prepare a suspension of $250 \mu \mathrm{L}$ of glutathione Sepharose slurry in $2250 \mu \mathrm{L}$ of bacterial lysis buffer. Allow equilibration of the beads in lysis buffer for $10 \mathrm{~min}$. Load $500 \mu \mathrm{L}$ of this suspension into each column. This will ensure that each column receives the same amount of agarose beads. Remove lysis buffer by gravity flow and apply bottom plug to column.

5. Load $700 \mu \mathrm{L}$ of bacterial lysate containing GST-WASPCRIB fusion protein onto each column, cap and allow coupling of fusion protein to the beads on a rotator for $1 \mathrm{~h}$ at $4^{\circ} \mathrm{C}$.

6. Remove bottom plug and cap from column. Clear bacterial lysate by gravity flow.

7. Wash beads 4 times with washing buffer by gravity flow. Apply bottom plug to column.

8. Equilibrate beads with $600 \mu \mathrm{L}$ of $1 \times$ reaction buffer for $10 \mathrm{~min}$. Remove reaction buffer by gravity flow and apply bottom plug to column

9. Label microcentrifuge tubes with $0,5,10,15$ and $20 \mathrm{sec}$. Dispense $175 \mu \mathrm{L}$ of $5 \times$ reaction buffer and keep on ice.

10. Harvest and resuspend cells at $4 \times 10^{7}$ cells $/ \mathrm{mL}$ in Soerensen buffer.

11. Transfer $700 \mu \mathrm{L}$ of cell suspension into the time 0 tube containing $5 \times$ reaction buffer. Mix well on a Vortex. Stimulate $5 \mathrm{~mL}$ of cell suspension with $50 \mu \mathrm{L}$ of 0.1 mM cAMP (1 $\mu \mathrm{M}$ final concentration). Mix well.

12. Immediately transfer $700-\mu \mathrm{L}$ samples at $5,10,15$ and $20 \mathrm{sec}$ into the corresponding tubes containing $5 \times$ reaction buffer. Mix well on a Vortex and place samples on ice.

13. Transfer $700 \mu \mathrm{L}$ of cell lysate onto the corresponding spin column containing the fusion protein coupled to glutathione Sepharose beads (see steps 4-8). Cap and incubate for $45 \mathrm{~min}$ on a rotator at $4^{\circ} \mathrm{C}$.

14. Remove a $50-\mu \mathrm{L}$ sample from the time point 0 lysate and mix with $50 \mu \mathrm{L}$ of $2 \times$ SDS sample buffer. This sample will be used to monitor total Rac1.

15. Remove bottom plug and cap from columns. Release lysate from column by gravity flow.

16. Wash columns 4 times with $1 \times$ reaction buffer by gravity flow. Place the spin column in an open microcentrifuge cup and remove residual reaction buffer by spinning at $10,000 \times g$ for $1 \mathrm{~min}$. 
17. Place the spin columns into clean labeled microcentrifuge cups, apply $50 \mu \mathrm{L}$ of $2 \times$ SDS sample buffer and spin at $10,000 \times g$ for 1 min to collect protein complexes.

18. Denature samples for $5 \min$ at $95^{\circ} \mathrm{C}$. Load $15 \mu \mathrm{L}$ of each sample onto $18 \%$ polyacrylamide gels, resolve by SDS-PAGE and detect Rac1 by Western blotting with antibody 273-461-3 (15) using standard procedures.

19. Quantitate the intensity of the Rac1 bands by densitometry and refer the values to the value of the 0 time point (see Note 12) (Fig. 1B).

\subsection{Monitoring Rac activity in live cells}

In order to monitor the localization and activity of Rho GTPases in living $D$. discoideum cells, a number of GBDs fused to fluorescent proteins have been used (see Subheading 1.3.3 and Table 1). Here we describe the construction of a probe consisting of DYFP fused C-terminally to the GBD of protein kinase DPAKa (aa 731890). We then describe how to determine the relative intensity distribution of the DPAKa(GBD)-DYFP probe in the plasma membrane, and illustrate its use in estimating Rac1 activation upon stimulation of cells with chemoattractant pulses.

\subsubsection{Construction of the DPAKa(GBD)-DYFP probe}

The probe for active Rac1 is constructed by two step cloning: (a) insertion of DYFP in the extrachromosomal pDM304 vector (20) to obtain a vector with C-terminal DYFP tag followed by (b) insertion of the GBD domain of DPAKa in pDM304 C-terminal DYFP vector. Optionally, this protocol can be adapted to create probes with any tag. It is possible to carry out step (b) on predesigned vectors that already contain a tag of choice, if available (see Note 13).

1. Design and order a PCR primer pair for amplification of the DYFP tag (see Note 14).

2. Amplify DYFP in a 100- $\mu \mathrm{L}$ PCR reaction from $1 \mathrm{ng}$ of template vector according to standard procedures (see Note 15).

3. Resolve the PCR reaction on a $1 \%$ agarose gel electrophoresis. Stain the gel with ethidium bromide to determine the amount and size of the PCR product. 
4. Using a UV transilluminator and a scalpel, cut out the band corresponding to the PCR product and extract it from the gel using a gel extraction kit according to the manufacturer's instructions.

5. Digest the extracted PCR product with Spel and Xbal restriction endonucleases in a total reaction volume of $100 \mu \mathrm{L}$ according to manufacturer's instructions.

6. Purify the digested PCR product using a PCR purification kit according to the manufacturer's instructions.

7. Run a $1 \%$ agarose gel electrophoresis with a small volume of purified digested PCR product and stain gel with ethidium bromide to estimate its amount. Alternatively measure the concentration spectrophotometrically. Store the prepared PCR product at $-20^{\circ} \mathrm{C}$.

8. Digest $10 \mu \mathrm{g}$ of pDM304 vector with Spel restriction endonuclease in a total reaction volume of $100 \mu \mathrm{L}$ according to manufacturer's instructions (see Note 16).

9. Run a $1 \%$ agarose gel electrophoresis with a small volume of the digestion reaction and stain the gel with ethidium bromide to confirm complete vector digestion.

10. Purify the digested vector using a PCR purification kit according to the manufacturer's instructions.

11. Dephosphorylate the digested vector with $1 \mu \mathrm{L}$ of alkaline phosphatase in a total reaction volume of $100 \mu \mathrm{L}$ according to manufacturer's instructions.

12. Purify the dephosphorylated digested vector using a PCR purification kit according to the manufacturer's instructions.

13. Run an agarose gel electrophoresis with a small volume of dephosphorylated digested vector and stain the gel with ethidium bromide to quantify its amount, Alternatively measure the concentration spectrophotometrically. Store the prepared vector at $-20^{\circ} \mathrm{C}$.

14. Set up a ligation reaction composed of $100 \mathrm{ng}$ of dephosphorylated digested vector and a 5-fold excess of digested PCR product according to the ligase manufacturer's instructions.

15. Thaw an aliquot of electrocompetent $\mathrm{DH} 5 \alpha$ bacteria on ice.

16. Add $1 \mu \mathrm{L}$ (or more) of the ligation reaction to the thawed $\mathrm{DH} 5 \alpha$ bacteria. Transfer mixture to a precooled 2-mm gap electroporation cuvette and keep on ice. 
17. Electroporate the cells using a pre-set protocol for E.coli (e.g. $2.5 \mathrm{kV}, 400 \Omega$ and $25 \mu \mathrm{F})$.

18. Add $1 \mathrm{~mL}$ of SOC medium to the cuvette, mix and transfer the mixture to a microcentrifuge tube. Incubate bacteria at $37^{\circ} \mathrm{C}$ for $1 \mathrm{~h}$ to recuperate.

19. Spread the bacteria on LB agar plates supplemented with $100 \mu \mathrm{g} / \mathrm{mL}$ ampicillin and incubate overnight at $37^{\circ} \mathrm{C}$ (see Note 17 ).

20. Pick single colonies (usually 10) from agar plates, inoculate in $4 \mathrm{~mL}$ of LB medium supplemented with $100 \mu \mathrm{g} / \mathrm{mL}$ ampicillin and grow overnight at $37^{\circ} \mathrm{C}$ with shaking.

21. Isolate vector DNA using a plasmid miniprep kit following the manufacturer's instructions.

22. Identify pDM304 C-terminal DYFP vectors with DYFP insert ligated into proper orientation by restriction digestion. Save the bacterial clones carrying the correct vector (see Note 18).

23. Send vector(s) for sequencing to verify the precise order of nucleotide bases.

24. For the next step of cloning, design and order a PCR primer pair for amplification of the GBD from DPAKa (see Note 19).

25. Amplify the DPAKa(GBD) in a 100- $\mu \mathrm{L}$ PCR reaction from $1 \mathrm{ng}$ of template vector according to standard procedures. Alternatively, cDNA instead of plasmid can also be used as a template.

26. Proceed as in steps 3-7.

27. Sequentially digest $10 \mu \mathrm{g}$ of pDM304 C-terminal DYFP vector with BgllI and Spel restriction endonucleases according to manufacturer's instructions. Between digestions it is necessary to purify the digested vector as in step 10.

28. Proceed as in steps 9-13.

29. Set up a ligation reaction composed of $100 \mathrm{ng}$ of dephosphorylated digested pDM304 C-terminal DYFP and a 5-fold excess of digested DPAKa(GBD) according to the ligase manufacturer's instructions.

30. Proceed as in steps 15-21.

31. Identify pDM304 C-terminal DYFP vectors containing DPAKa(GBD) insert by restriction digestion. Save the bacterial clones carrying the correct vector (see Note 18). 
32. Send the vector for sequencing to verify the precise order of nucleotide bases.

33. Electroporate $D$. discoideum cells with $5 \mu \mathrm{g}$ of pDM304 DPAKa(GBD)-DYFP vector by a standard procedure (21).

34. 5-18 $\mathrm{h}$ after transfection start selection by adding G418 to a final concentration of $10 \mu \mathrm{g} / \mathrm{mL}$ (see Note 20).

\subsubsection{Analysis of the relative Rac activity in the cell membrane}

The DPAKa(GBD)-DYFP probe is strongly enriched in the cell plasma membrane where it binds to the active, GTP-bound form of Rac1 GTPases (Fig. 2). Its average fluorescence intensity is more than 4 times higher in the membrane compared to the cytoplasmic background, and can attain up to 20 times higher values. In the following we describe how to monitor the DPAKa(GBD)-DYFP-expressing cells using confocal microscopy, and quantitatively analyse its distribution along the two-dimensional cross-section of the plasma membrane.

1. Place the cells into an appropriate observation chamber, filled with either Soerensen buffer or low-flourescence growth medium. For high-resolution microscopy a chamber glass bottom of the thickness \#1.5 $(0.17 \mathrm{~mm})$ should be used. The temperature in the chamber should be the room temperature regularly used for cell cultivation $\left(21-23^{\circ} \mathrm{C}\right)$ (see Note 21$)$.

2. Perform confocal microscopy using either a water-immersion or an oil-immersion high-NA objective. Because of the thinness of the labeled structure, it is advisable to set the pixel size between 50 and $100 \mu \mathrm{m}$, thereby maintaining a tolerable level of phototoxicity and photobleaching (see Note 22). Adjust the detector's offset and gain levels according to the transient local maximal brightness of the probe, ensuring that the signal remains in the range of the detector's linear response. When recording longer time series, correct for photobleaching based on the decay of the fluorescence in the cytoplasm.

3. Analyse the cell images by image-processing software capable of automatically extracting the bright contour of the cell that corresponds to the plasma membrane. We use the ImageJ plugin QuimP, a software package which enables extraction of the cell contour, and sampling of the fluorescence intensity at an adjustable number of points along the contour (Fig. 3A) (22). QuimP is 
capable of analysing long series of images with a small extent of manual intervention (see Note 23). It consists of four sub-plugins that correspond to four stages of analysis.

a. Cell segmentation, as the first stage, is performed by the BOA sub-plugin. Outputs are global measures, such as displacement of the cell centroid.

b. ECMM Mapping sub-plugin performs membrane tracking in which cell outlines are mapped between frames to extract local membrane velocities.

c. Measuring fluorescence intensities is performed by the ANA sub-plugin.

d. Finally, data analysis is performed by the Q Analysis sub-plugin. Alternatively, data from the output files generated by BOA, ECMM and ANA plugins can be directly read into Matlab ${ }^{\mathrm{TM}}$, where custom scripts can be used for more in-depth analysis. For example, it is possible to plot the data representing the relative fluorescence intensity along the membrane either for single cell images (Fig. 3B) or for the entire time series in the form of a kymograph (Fig. 3C).

\subsubsection{Membrane recruitment of active Rac upon chemoattractant stimulation} In addition to analyzing the activation of Rac1 upon agonist stimulation using a pulldown assay (see Subheading 3.3.2), the same response can be analyzed in living cells by measuring the recruitment of active Rac1 to the cell membrane upon pulse stimulation by a chemoattractant, either folic acid in vegetative cells or cAMP in aggregation-competent cells. Using a probe specific for activated Rac1 such as DPAKa(GBD)-DYFP, it can be shown that Rac1 activation is accompanied by translocation of the probe to the plasma membrane, consistent with the view that the activation of Rac GTPases by guanine nucleotide exchange factors takes place at the membrane. The following protocol describes how to perform a simple assay of the agonist-stimulated membrane recruitment of Rac1 in $D$. discoideum cells.

1. Prepare a microscopy chamber with a small volume of cell suspension (typically less than $100 \mu \mathrm{L}$ ) and allow at least 15 min for the cells to settle (see Note 3). Mount the chamber on the confocal microscope and adjust the recording parameters (see Subheading 3.4.2, steps 1-2). While adjusting the gain take into 
account that the maximal signal intensity in the membrane can increase by a factor of 2 or more upon stimulation.

2. Calculate the amount of the stock solution of either folic acid or cAMP that has to be added to the chamber to reach the final desired concentration. We typically adjust the final concentration of folic acid to $50 \mu \mathrm{M}$ and of cAMP to $30 \mu \mathrm{M}$ (see Note 24).

3. Start recording the selected cell(s) for at least 20 seconds and then rapidly add the chemoattractant (see Note 24). Make a note of the time when chemoattractant was added and continue to record at least for another minute using the fastest recording frequency that still yields acceptable image quality (see Note 25). A normal response in wild-type cells will subside in approximately 20 seconds, but can be prolonged or augmented in mutated or pharmacologically treated cells.

4. Proceed with the image analysis using the QuimP software (see Subheading 3.4.2 step 3). Since recruitment of the probe to the membrane is fairly uniform, it is sufficient to determine the integrated fluorescence intensity in the membrane. In this type of experiment it is also necessary to determine the total fluorescence intensity in the cytoplasm for each frame, which is a feature integrated into QuimP.

\section{Notes}

1. Caution should be exerted while working with phalloidin and methanol. Phalloidin is very toxic, may be fatal if swallowed, inhaled or absorbed through the skin. For personal protection, wear glasses and gloves. Avoid dispersal of material in the air or on working surfaces. Methanol is toxic, may cause heart and liver damage, blindness or death if ingested or inhaled. Methanol is highly flammable. The flame above burning methanol is invisible. Always wear safety glasses, clear any source of ignition from the working area, and ensure the working area is well ventilated.

2. The amount of phalloidin present in the stop solution should be such that it saturates the amount of F-actin of the cells. The concentration given here works 
well for the number of cells indicated in the protocols but may need to be adjusted if substantial changes are introduced (23).

3. Besides using commercially available cell chambers with a glass bottom, a simple reusable chamber can be constructed by affixing a plastic ring to a $24 \mathrm{~mm}$ wide coverslip by silicon grease.

4. TRITC-phalloidin is expensive, thus prepare the volume of stop solution needed for the number of samples in an experiment plus some excess. Leftover stop solution containing TRITC-phalloidin can be stored at $-20^{\circ} \mathrm{C}$ and used in the next experiment by mixing the leftover with the new stop solution, which will make a homogeneous stop solution.

5. Use a shaker with low amplitude of displacement, like the ones designed for shaking ELISA plates. Adjust rotation speed so that the cell suspension is visibly shaking to prevent cells from settling while avoiding spilling of the cell suspension.

6. Measurements of four samples at time point 0 are important to obtain an accurate estimate of the basal amount of F-actin prior to CAMP stimulation. Avoid collecting time point 0 samples from the cell suspension before transferring into the 24-wells, as values will differ. All samples of one experiment should be collected from the same well holding a 1-mL aliquot of cell suspension.

7. To achieve accurate sample collection at the recommended time points, it is essential to stay attentive near the shaker, keep tubes containing stop solution open and a pipette ready to withdraw samples and dispense them into the corresponding tubes once cAMP has been added. Avoid contact of the pipette tip with the stop solution, use the same tip used to take the time point 0 samples throughout collection of all time points. Vortexing of samples is dispensable, because lysis occurs immediately upon contact with the stop solution. The sample at time point $5 \mathrm{sec}$ is critical, as the first peak of polymerization is expected in this sample.

8. Bacterial pellets obtained after protein expression can be stored at $-20^{\circ} \mathrm{C}$ for processing at a later step.

9. Parameters for sonication need to be adjusted to the device available. Bacterial lysis can be achieved by other methods (freezing and thawing, French press).

10. It is more convenient to store bacterial supernatant for attachment to Sepharose beads freshly prior to the pull-down assay rather than to store a batch of purified 
fusion protein, as this would need to be dialyzed to remove glutathione and will have to be attached to beads anyway. It is also not advisable to store coupled beads.

11. The amount of fusion protein pulled down using glutathione Sepharose beads can be estimated by comparison to a bovine serum albumin standard resolved on the same SDS-PAGE, followed by Coomassie staining.

12. Several exposure times should be used when documenting the detected Rac1 in the Western blots by conventional X-ray film development so that the density of the protein bands varies linearly with the amount of protein on the blot.

Alternatively, a quantitative detection system based on secondary fluorescent antibodies may be used.

13. DYFP was selected as the tag of choice because it enables prolonged live cell imaging since $D$. discoideum cells are much more sensitive to illumination by excitation wavelengths for CFP and GFP. Also, it is advisable to label the selected Rac-binding domain with a fluorescent protein both at its $\mathrm{N}$ - and $\mathrm{C}$-termini and check their respective localizations in cells to rule out a possible steric inhibition of binding of the probe to its target GTPase.

14. The forward primer should be designed to contain (a) three nucleotide bases as an overhang, (b) Spel recognition site, and (c) the nucleotide bases AGT as a part of a linker. No Start codon is necessary. The reverse primer should contain (a) a Stop codon, (b) Xbal recognition site and (c) three nucleotide bases as an overhang. It is also important to verify that the insert one wishes to amplify does not contain recognition sites for the restriction enzymes to be used for cloning.

15. The template vector is any vector that carries the sequence of DYFP or any other tag you wish to amplify.

16. DNA digestion with Spel and Xbal enzymes yields compatible ends such that the insert can be ligated into the vector digested with only Spel. In this case, the orientation of the ligated insert has to be verified.

17. If you wish to use a vector with a different resistance marker, change the antibiotic accordingly.

18. The bacterial strain carrying the constructed vector can be stored in the form of a bacterial glycerol stock for long-term storage. Glycerol stocks are 
made by mixing $1.4 \mathrm{~mL}$ of overnight liquid bacterial culture with $0.6 \mathrm{~mL}$ of $50 \%$ sterile glycerol solution. Store at $-80^{\circ} \mathrm{C}$.

19. The forward primer should contain (a) three nucleotide bases as an overhang, (b) Bglll recognition site, (c) AAAAA sequence, and (d) a Start codon. The reverse primer should contain (a) Spel recognition site and (b) three nucleotide bases as an overhang. No in frame Stop codon should be present.

20. First transfectant colonies usually appear 4 days after transfection and clonal selection is not required.

21. Although $D$. discoideum cells are standardly cultivated at ambient temperatures that can be regulated by air-conditioning devices, more stable experimental conditions can be obtained by using table-top or enclosure-type environmental chambers for microscopy. Special care should be taken to prevent heating of the focal volume via heat conduction through the objective and the immersion liquid, which can be avoided by using objective-cooling devices. Also, in order to minimize phototoxicity, we recommend to use low-fluorescence growth medium, which can be obtained, e.g., from Formedium.

22. Such sub-Nyquist pixel size will also facilitate a possible digital post-processing of images, e.g. using deconvolution algorithms. In order to minimize phototoxicity and photobleaching, keep the illumination intensity at a practical minimum, while maintaining an acceptable signal-to-noise ratio in the image.

23. Results of the automatic contour extraction should be inspected frame-by-frame and corrected if necessary using tools provided by QuimP. For typical cells, we find manual intervention needed in less than $5 \%$ of analyzed images.

24. We usually perform uniform stimulation of vegetative cells with folic acid by rapidly adding $10 \mu \mathrm{L}$ of $250 \mu \mathrm{M}$ folic acid solution to $40 \mu \mathrm{L}$ of cell suspension in Soerensen buffer. We perform uniform stimulation with cAMP by rapidly adding $10 \mu \mathrm{L}$ of $150 \mu \mathrm{M}$ cAMP solution to $40 \mu \mathrm{L}$ of cell suspension in Soerensen buffer.

25. Quick pipetting of the chemoattractant solution into the cell suspension can detach the cells from the coverslip, therefore the direction and speed of the outflow should be carefully adjusted. Also, significant addition of material into the chamber can shift the position of the observed cell out of focus; the use of an autofocusing device is therefore recommended. 


\section{Acknowledgements}

M.M. and I.W. were supported by the Croatian Science Foundation under the project IP-2014-09-4753. We thank Marko Šoštar for help in preparing Figure 3.

\section{References}

1. Kessin, R. (2001) Dictyostelium - Evolution, cell biology, and the development of multicellularity. Cambridge Univ. Press, Cambridge.

2. Müller-Taubenberger, A., Kortholt, A., and Eichinger, L. (2013) Simple system substantial share: the use of Dictyostelium in cell biology and molecular medicine. Eur J Cell Biol 92, 45-53.

3. Eichinger, L., and Rivero, F. (eds) (2006) Dictyostelium discoideum protocols, Humana Press, Springer Verlag, Heidelberg.

4. Eichinger, L., and Rivero, F. (eds) (2013) Dictyostelium discoideum protocols 2nd Edition. Humana Press, Springer Verlag, Heidelberg.

5. Vlahou, G., and Rivero, F. (2006) Rho GTPase signaling in Dictyostelium discoideum: insights from the genome. Eur J Cell Biol 85, 947-59.

6. Rivero, F., and Xiong, H. (2016) Rho signaling in Dictyostelium discoideum. Int Rev Cell Mol Biol 322, 61-122.

7. Hall, A., Schlein, A., and Condeelis, J. (1988) Relationship of pseudopod extension to chemotactic hormone-induced actin polymerization in amoeboid cells. J Cell Biochem 37, 285-299.

8. Howard, T., and Oresajo, C. (1985) The kinetics of chemotactic peptide-induced change in F-actin content, F-actin distribution, and the shape of neutrophils. $J$ Cell Biol 101,1078-1085.

9. Park, K.C., Rivero, F., Meili, R., Lee, S., Apone, F., and Firtel, R.A. (2004) Rac regulation of chemotaxis and morphogenesis in Dictyostelium. EMBO J 23, 4177-4189.

10. Han, J.W., Leeper, L., Rivero, F., and Chung, C.Y. (2006) Role of RacC for the regulation of WASP and phosphatidylinositol 3-kinase during chemotaxis of Dictyostelium. J Biol Chem 281, 35224-35234.

11. Somesh, B.P., Vlahou, G., lijima, M., Insall, R.H., Devreotes, P., and Rivero, F. (2006) RacG regulates morphology, phagocytosis, and chemotaxis. Eukaryot Cell 5, 1648-1663.

12. Bernard, V., Bohl, B., and Bokoch, G. (1999) Characterization of rac and cdc42 
activation in chemoattractant-stimulated human neutrophils using a novel assay for active GTPases. J Biol Chem 274, 13198-13204.

13. Vlahou, G., Schmidt, O., Wagner, B., Uenlue, H., Dersch, P., Rivero, F., and Weissenmayer, B.A. (2009) Yersinia outer protein YopE affects the actin cytoskeleton in Dictyostelium discoideum through targeting of multiple Rho family GTPases. BMC Microbiol 9, 138.

14. Filić, V., Marinović, M., Faix, J. and Weber, I. (2014) The IQGAP-related protein DGAP1 mediates signaling to the actin cytoskeleton as an effector and a sequestrator of Rac1 GTPases. Cell Mol Life Sci 71, 2775-2785.

15. Dumontier, M., Hocht, P., Mintert, U., and Faix, J. (2000) Rac1 GTPases control filopodia formation, cell motility, endocytosis, cytokinesis and development in Dictyostelium. J. Cell Sci 113, 2253-2265.

16. Filić, V., Marinović, M., Faix, J. and Weber, I. (2012) A dual role for Rac1 GTPases in the regulation of cell motility. J Cell Sci 125, 387-398.

17. Veltman, D.M., King, J.S., Machesky, L.M., and Insall, R.H. (2012) SCAR knockouts in Dictyostelium: WASP assumes SCAR's position and upstream regulators in pseudopods. J Cell Biol 198, 501-508.

18. Chung, C.Y., Feoktistov, A., Hollingsworth, R.J., Rivero, F., and Mandel, N.S. (2013) An attenuating role of a WASP-related protein, WASP-B, in the regulation of F-actin polymerization and pseudopod formation via the regulation of RacC during Dictyostelium chemotaxis. Biochem Biophys Res Commun 436, 719-724.

19. Marinović, M., Šoštar, M., Filić, V., Antolović, V., and Weber, I. (2016) Quantitative imaging of Rac1 activity in Dictyostelium cells with a fluorescently labelled GTPase-binding domain from DPAKa kinase. Histochem Cell Biol 146, 267-279.

20. Veltman, D.M., Akar, G., Bosgraaf, L., and van Haastert, P.J.M. (2009) A new set of small, extrachromosomal expression vectors for Dictyostelium discoideum. Plasmid 61, 110-118.

21. Faix, J., Linkner, J., Nordholz, B., Platt, J.L., Liao, X.H., and Kimmel, A.R. (2013) The application of the Cre-loxP system for generating multiple knock-out and knock-in targeted loci. Methods Mol Biol 983, 249-267.

22. Dormann, D., Libotte, T., Weijer, C.J., and Bretschneider, T. (2002) Simultaneous quantification of cell motility and protein-membrane-association using active contours. Cell Motil Cytoskeleton 52, 221-230.

23. Condeelis, J., and Hall, A. (1991) Measurement of actin polymerization and cross-linking in agonist-stimulated cells. Methods Enzymol 196, 486-496.

24. de la Roche, M., Mahasneh, A., Lee, S. F., Rivero, F., and Côté, G. P. (2005) 
Cellular distribution and functions of wild-type and constitutively activated Dictyostelium PakB. Mol Biol Cell 16, 238-47. 


\section{Figure Legends}

Fig. 1 Reduced actin polymerization response and Rac1 activation upon cAMP stimulation in cells expressing YopE. YopE is an effector protein produced by pathogenic bacteria of the genus Yersinia. It displays GTPase activating activity on several Rho GTPases. A GFP fusion of YopE was expressed in D. discoideum cells using a tetracycline-regulatable vector. (A) Relative F-actin content as determined by TRITC-phalloidin staining of aggregation competent cells upon stimulation with $1 \mu \mathrm{M}$ cAMP. Control cells are non-induced cells carrying the GFP-YopE plasmid. The amount of F-actin was normalized relative to the F-actin level of non stimulated cells. Data are average \pm standard deviation of 5 independent experiments. For simplicity, error bars are depicted only in one direction. ${ }^{*} P<0.05$, Student's t-test. (B) Activation of Rac1 upon cAMP stimulation in cells expressing GFP-YopE. Rac1-GTP was separated using a pulldown assay with GST-WASPCRIB. A representative blot of each strain is shown. Data are average \pm standard deviation of four independent pull down experiments. ${ }^{*} \mathrm{P}<0.05$, Student's t-test. Reproduced from ref. 13.

\section{Fig. 2 Localization of a DPAKa(GBD)-DYFP probe that specifically monitors} active Rac1 in living $\boldsymbol{D}$. discoideum cells. Localization of DPAKa(GBD)-DYFP probe during (from left to right): cell migration, cytokinesis, phagocytosis of yeast particles (red), and macropinocytosis. Scale bar represents $10 \mu \mathrm{m}$.

Fig. 3 Quantitative analysis of the fluorescence intensity in the cortex of cells expressing the DPAKa(GBD)-DYFP probe. (A) The outline of a cell's contour automatically determined by QuimP is represented by a subset of resulting nodes. The node labeled with the cross represents an arbitrary starting coordinate $(x=0)$. Scale bar represents $10 \mu \mathrm{m}$. (B) A plot of the normalized cortical intensity along the contour of the cell shown in the panel A traced in the clockwise direction from the position $x=0$. (C) Spatio-temporal dynamics of the normalized cortical intensity displayed in the form of a kymograph. The intensity $I_{N}$ along the cell contour ( $x$-axis) has been sampled every 3 seconds and plotted against time (y-axis). 